\title{
The Effect of Polycaprolactone Nanofibers on the Dynamic and Impact Behavior of Glass Fibre Reinforced Polymer Composites
}

\author{
Cristobal Garcia ${ }^{1, *(\mathbb{D})}$, Irina Trendafilova ${ }^{1}$ (D) and Andrea Zucchelli ${ }^{2}$ \\ 1 Department of Mechanical and Aerospace Engineering, University of Strathclyde, 75 Montrose Street, \\ Glasgow G1 1XJ, UK; irina.trendafilova@strath.ac.uk \\ 2 Department of Industrial Engineering, University of Bologna, Viale Risorgimento 2, 40125 Bologna, Italy; \\ a.zucchelli@unibo.it \\ * Correspondence: cristobal.garcia@strath.ac.uk; Tel.: +44-141-548-5025
}

Received: 13 June 2018; Accepted: 18 July 2018; Published: 23 July 2018

\begin{abstract}
In this article, the effect of polycaprolactone nanofibers on the dynamic behavior of glass fiber reinforced polymer composites is investigated. The vibratory behavior of composite beams in their pristine state (without any nano modification) and the same beams modified with polycaprolactone fibers is considered experimentally. The experimental results show that the incorporation of polycaprolactone nanofibers increases the damping; however, it does not significantly affect the natural frequencies. Additionally, the paper analyses the effect of polycaprolactone nanofibers on the impact behavior of glass fiber/epoxy composites. This has already been analyzed experimentally in a previous study. In this work, we developed a finite element model to simulate the impact behavior of such composite laminates. Our results confirm the conclusions done experimentally and prove that composites reinforced with polycaprolactone nanofibers are more resistant to damage and experience less damage when subjected to the same impact as the pristine composites. This study contributes to the knowledge about the dynamic behavior and the impact resistance of glass fiber reinforced polymer composites reinforced with polycaprolactone nanofibers. The findings of this study show that interleaving with polycaprolactone nanofibers can be used to control the vibrations and improve the impact damage resistance of structures made of composite mats as aircrafts or wind turbines.
\end{abstract}

Keywords: composite materials; nano composites; dynamic behavior; impact behavior; finite element model; electrospinning

\section{Introduction}

Composite laminates reinforced with polymeric electrospun nanofibers are attracting increasing attention among the scientific community due to their superior material properties. It is well known that the incorporation of electrospun nanofibers into the interfaces of composite laminates can drastically change/improve some material properties. For example, the inclusion of polycaprolactone nanofibers in the interfaces of composite laminates can be used to increase the mode I fracture toughness up to $50 \%$ [1]. The introduction of tetraethyl orthosilicate electrospun nanofibers in the epoxy resin of glass fiber composites was found to enhance the interlaminar shear strength up to $15 \%$ [2]. Core-shell polyamide nanofibers can be used to prepare flame-retardant polymer nanofibers [3], which can be potentially used to develop composite laminates with enhanced flame retardancy. Thus, electrospun nanofibers offer great potential to improve some structural properties of composite mats $[4,5]$. 
In the last years, the dynamic properties of composite laminates have been widely studied because of their applications in delamination detection [6] and structural health monitoring [7]. However, only several studies have investigated the vibratory behavior of composites reinforced with electrospun nanofibers. For example, the authors of [8] demonstrated that the incorporation of nylon nanofibers in glass fiber composite mats increases the damping ratio; however, it does not considerably affect the natural frequencies. Similar results were found in [9], where an important increase of the damping ratio in carbon fiber composite laminates due to the incorporation of nylon nanofibers is found. To date, the dynamic and vibratory behavior of composite laminates reinforced with electrospun nanofibers has been poorly investigated. Therefore, there is an urgent need to explore the effect of electrospun nanofibers (e.g., polycaprolactone or polyamide) on the vibration properties of composite laminates.

In the last decade, several papers have investigated the effect of electrospun nanofibers on the mechanical properties of composite laminates. For example, the authors of [10] investigated the effect of nylon nanofibers on the interlaminar properties of glass fiber/epoxy laminates. The results reveal that the addition of nylon nanofibers increased the mode I and mode II energy releases rates by $62 \%$ and $109 \%$, respectively. Other works such as [11] reported that the maximum stress of carbon fiber composites is significantly enhanced (with an increment of 35\%) due to the incorporation of nylon polymer nanofibers into the composite laminates. To date, most of the studies have investigated the effect of electrospun nanofibers on the fracture toughness in opening and sliding mode [12,13], on the interlaminar shear strength [14], on the tensile strength [15], and the compression strength after impact [16]. However, there are still very few works that have reported the effect of electrospun nanofibers on the impact behavior of composite laminates.

In this work, the authors experimentally investigate the influence of polycaprolactone nanofibers on the vibratory properties of glass fiber reinforced polymer composites. For that purpose, composite beams without nanofibers (which will be referred to as pristine) and with polycaprolactone nanofibers (referred to as nano) are subjected to free vibration tests. Subsequently, the vibration signals of the pristine and nano composites are acquired through an accelerometer. The signals are further analyzed to evaluate the natural frequencies and the damping ratio of the two types of specimens. The main goal is to assess the influence of polycaprolactone nanofibers on the natural frequencies and damping ratio of the glass fiber epoxy composite beams. To the best of our knowledge, this work is the first attempt to study the vibratory behavior of composites reinforced with polycaprolactone nanofibers.

The second part of the manuscript numerically analyzes the effect of polycaprolactone nanofibers on the impact behavior of glass fiber reinforced composites. For this study, a finite element model is used to evaluate the impact response of composites with and without polycaprolactone nanofibers. The numerical results obtained are compared to the experimental results published by [17] and they show quite good agreement regarding the impact damaged area of the pristine and the nano modified specimens. Both the experimental and the numerical results show that the incorporation of polycaprolactone nanofibers in the composite interfaces significantly enhances the impact damage resistance of the glass fiber composites. On the basis of these results, it can be concluded that composites reinforced with polycaprolactone nanofibers are less prone to impact damage than the pristine composites. As far as the authors are aware, this is the first time that a finite element model is used to simulate the impact damage resistance of composites reinforced with polycaprolactone nanofibers.

The main contributions of this study are twofold: Firstly, the paper demonstrates that the interleaving with polycaprolactone nanofibers can be used to reduce the composite vibrations, which have important applications for composite structures in which vibrations are a source of problems. Secondly, the paper reveals that the addition of polycaprolactone nanofibers can also be used to develop composite structures with a higher resistance to impacts (e.g., bird strikes or hailstones), which is important for the health of the composite mats used in aircrafts, wind turbines, and other civil structures.

The rest of the manuscript is organized as follows: The second section is devoted to the fabrication of the pristine and nano-modified composites. The third section explains the methodology used to assess the natural frequencies and the damping ratio of the composite beams. Section 4 presents the finite element 
model used to simulate the impact response of the composite specimens. Section 5 presents and discusses in detail the experimental and numerical results. The last section offers some conclusions.

\section{Fabrication of Composites with and without Polycaprolactone Nanofibers}

This section describes the fabrication of the glass fiber/epoxy composites reinforced with and without polycaprolactone nanofibers. Figure 1 illustrates the composite lay-up of the pristine and nano-modified composites used in this study. Pristine composites (without polycaprolactone nanofibers) were fabricated by hand lay-up of eight layers of unidirectional glass fiber epoxy prepreg, as detailed in Figure 1a. The composite specimens are prepared with dimensions of $168 \mathrm{~mm} \times 32 \mathrm{~mm} \times 3.1 \mathrm{~mm}$ and stacking sequence $[0,90,0,90]_{s}$. After the lay-up, the composite beams are cured using a vacuum bag in an autoclave at $150^{\circ}$ for about one hour, as indicated in the supplier's specifications. The weight fractions of the glass fiber and epoxy resin are $78.6 \%$ and $21.4 \%$, respectively, for the pristine composites.

The nano composites (with polycaprolactone nanofibers) are also manufactured by hand lay-up with identical composite prepregs, number of layers, dimensions, ply orientations, and curing process as the pristine composites. However, six layers of polycaprolactone nanofibers are interleaved at each of the composite interfaces (excluding the central one), as shown in Figure 1b. It is also important to mention that the effect of the nanofibers on the final thickness of the composites is negligible (less than $1 \%$ ). Additionally, the difference in weight for the pristine and nano composites due to the incorporation of polycaprolactone nanofibers is also negligible. Therefore, the weight fraction of polycaprolactone nanofibers in the nano composites is very small (less than $1 \%$ ).

(a)

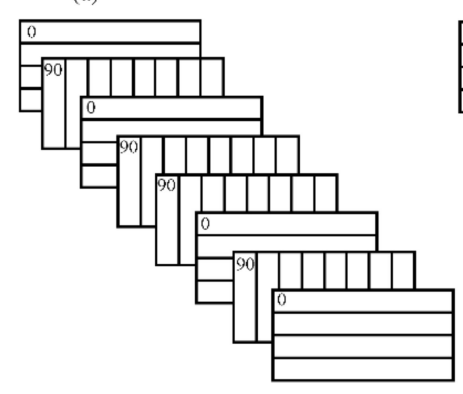

(b)

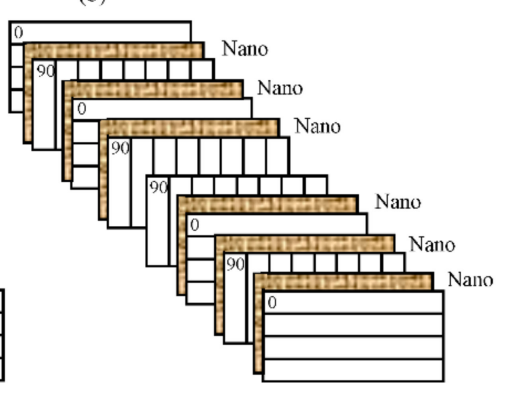

(c)

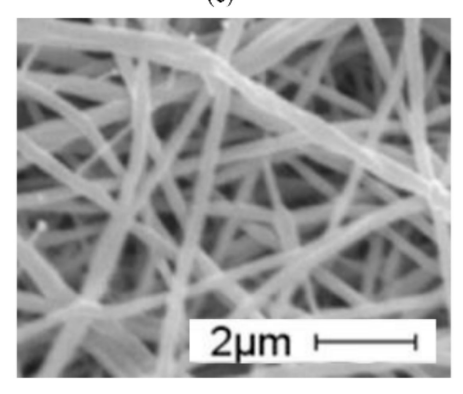

Figure 1. Composite lay-up of the (a) pristine and (b) nano modified composites. (c) Scanning electron microscope (SEM) image of polycaprolactone nanofibers as spun, adapted from figure in [17].

The layers of polycaprolactone nanofibers were prepared by the electrospinning technique [18]. This procedure was chosen because is an easy and low-cost technology to prepare polycaprolactone nanofibers with a wide variety of morphologies. For the preparation of the fibers, polycaprolactone pellets are dissolved in a solvent mixture of formic acid and acetic acid (60/40) at $15 \% \mathrm{w} / \mathrm{v}$. Subsequently, the chemical solution is transferred to a syringe to be spun using the following operational conditions: a high voltage of $23 \mathrm{kV}$, a feed rate of $0.9 \mathrm{~mL} / \mathrm{h}$, and a needle tip-collector distance of $15 \mathrm{~cm}$. As a result, an ultrathin layer of interconnected polycaprolactone nanofibers is obtained, as depicted in Figure 1c. The scanning electron microscope (SEM) image is adapted from [17] and shows a dense array of polycaprolactone nanofibers distributed randomly in the membrane. The diameter of the polycaprolactone nanofibers is $275 \mathrm{~nm}$, with a standard deviation of $75 \mathrm{~nm}$.

\section{Vibratory Behavior of Pristine and Polycaprolactone Nano-Modified Beams}

The aim of this section is to describe the vibration tests used to obtain the natural frequencies and the damping ratio of the pristine and polycaprolactone nano-modified composites. The experimental procedure used to measure the natural frequencies and the damping is given in Figure 2a and can be divided into four steps. First, the composite beams are fixed at both ends (clamped-clamped boundary conditions) using a test rig. The clamped regions are $8 \mathrm{~mm}$ long and the free span of the 
beams is $152 \mathrm{~mm}$. Second, an impact excitation is applied to the middle of the composite beam using a modal hammer. Third, the free vibration response of the composite specimens is measured by an accelerometer (RT-440 portable analyzer, SKF, Gotemburgo, Sweden). The vibration signals are recorded for $0.5 \mathrm{~s}$ at a sampling rate of $5 \mathrm{kHz}$, as shown in Figure $2 \mathrm{~b}$, and each measurement is repeated ten times per specimen. Finally, the free vibration responses (Figure $2 b$ ) are used to calculate the first five natural frequencies using the fast Fourier transform [19] and the damping via the logarithm decrement method [20].

(a)

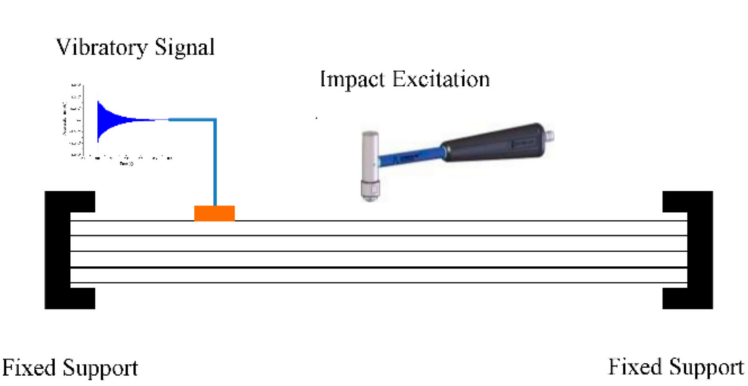

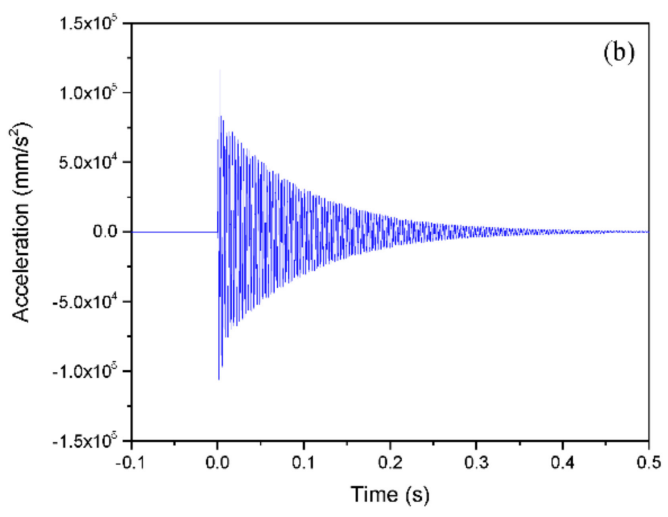

Figure 2. Schematic representation of the (a) vibration test used to measure the natural frequencies and damping in pristine and nano composites and (b) free vibration response of the composite specimens.

\section{Impact Behavior of Pristine and Polycaprolactone Nano-Modified Beams}

This section explains the methodology used to evaluate the impact response of the composites reinforced with and without polycaprolactone nanofibers. The section is organized as follows. The first part describes the finite element model used for studying the impact behavior of the composite specimens and the second part compares the results of the numerical model with available experimental data.

\subsection{Numerical (FE) Modelling}

This paragraph presents the finite element model used to simulate the impact damage resistance of the composite beams with and without polycaprolactone nanofibers. The composite laminates are modelled using ANSYS composite PrepPost. The layers of the composite laminates are modelled one by one including the ply thickness, stacking orientations, materials, and other heterogeneous features for each of the layers. The unidirectional glass fibre/epoxy layers are simulated using Solid 185 type elements and the material constants which are indicated in Table A1. The composite interfaces made of epoxy resin in the pristine composite and polycaprolactone nanofibers in the nano composite are modelled using cohesive elements.

Figure 3 represents the cohesive zone model used to simulate the initiation and the evolution of damage in the pristine and the nano-modified laminates. The cohesive model is based on the bilinear model proposed by Alfano and Crisfield [21]. From the figure, it can be deducted that the stiffness of the cohesive elements $\left(\mathrm{K}^{0}\right)$ is constant under small element displacements $\left(<\delta_{n, t^{*}}\right)$. However, the stiffness of the cohesive elements $\left(\mathrm{K}^{1}\right)$ decreases progressively when the level of displacement is above $\delta_{n, t^{*}}$. The figure also shows that the initiation of the damage is defined by the displacement at maximum cohesive traction $\left(\delta_{n, t^{*}}\right)$. Therefore, for small displacements below $\delta_{n, t^{*}}$, it is considered that there is no delamination/damage. As the material is non damaged, the stiffness is constant and equal to the original stiffness of the material. When the displacement of the elements is above $\delta_{n, t^{*}}$, the damage progresses with the increase of the displacement $\delta_{n, t}$ and accordingly, the stiffness goes down with a factor of $\left(1-D_{m}\right)$, as indicated in the equation shown in Figure 3. 


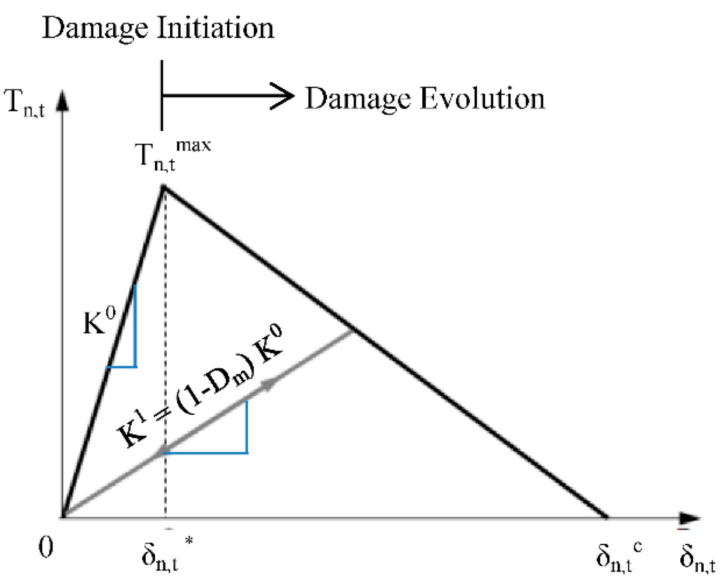

Figure 3. Schematic of the cohesive zone model used to simulate the composite interfaces.

The relation between the traction $\left(T_{n, t}\right)$ and the displacement $\left(\delta_{n, t}\right)$ of the cohesive elements can be defined using the following Equation (1).

$$
\frac{T_{n, t}}{\delta_{n, t}}=\left(1-D_{m}\right) K_{n, t}^{\circ}
$$

where $K_{n, t}^{\circ}$ represents the initial stiffness of the cohesive element and $\left(1-D_{m}\right)$ is a factor reduction of the stiffness due to the damage. The subscripts " $n$ " and " $t$ " refer to the normal and the tangential states. When the composites are undamaged, the damage parameter $\left(D_{m}\right)$ is 0 and the value of the stiffness is equal to the original stiffness. When the composites are damaged, the $D_{m}$ is between the two values 0 to 1 and the stiffness goes down, as indicated in Equation (1). Therefore, the level of damage is defined by the reduction of the stiffness. The value of $D_{m}=1$ corresponds to complete debonding, which corresponds to the critical displacement $\delta_{n, t^{\mathrm{c}}}$.

The corresponding cohesive parameters used to simulate the delamination between the composite interfaces for the pristine and the nano-modified composites are indicated in Table 1. From the table, it can be seen that the initial stiffness for the interfaces made of epoxy resin is $926 \mathrm{MPa} / \mathrm{mm}$, while the stiffness for the interfaces of polycaprolactone nanofibers is $533 \mathrm{MPa} / \mathrm{mm}$. The cohesive stiffness shows the same value for the normal and tangential components due to the isotropic nature of epoxy resin and the uniform distribution of polycaprolactone nanofibers in epoxy resin. The parameter alpha is defined as the ratio of $\delta_{n, t^{*}}$ to $\delta_{n, t^{\mathrm{c}}}$ (see Figure 3 ) and can be used to calculate $\delta_{n, t^{*}}$. This is of the utmost importance as the area under the triangle $0, \delta_{n, t^{*}}, T_{n, t}$ max on Figure 3 corresponds to the energy needed to initiate delamination and the area under the triangle $\delta_{n, t^{*}}, \delta_{n, t^{c}}{ }^{\mathrm{c}} T_{n, t}{ }^{\max }$ is associated with the energy for the damage propagation. The non-dimensional weighting parameter (betha) assigns different weights to the tangential and normal displacements, where we have assumed that the tangential and normal displacement contributes to the delamination (mixed mode debonding). The criteria used to select the material constants are shown in Appendix B.

Table 1. Cohesive zone parameters used to simulate the composite interfaces made of epoxy resin (pristine) and polycaprolactone nanofibers (nano).

\begin{tabular}{ccccc}
\hline Parameter & Abreviation & Pristine & Nano & Units \\
\hline Maximum Normal Traction & $T_{n}{ }^{\max }$ & 5 & 2.8 & $\mathrm{MPa}$ \\
Normal Displacement at Debonding & $\delta_{n}{ }^{\mathrm{c}}$ & 0.27 & 0.35 & $\mathrm{~mm}$ \\
Maximum Tangential Traction & $T_{t} \max$ & 5 & 2.8 & $\mathrm{MPa}$ \\
Tangential Displacement at Debonding & $\delta_{t}{ }^{\mathrm{c}}$ & 0.27 & 0.35 & $\mathrm{~mm}$ \\
Ratio & $\alpha$ & 0.02 & 0.015 & Dimensionless \\
Non-Dimensional Parameter & $\beta$ & 1 & 1 & Dimensionless \\
Initial Stiffness & $\mathrm{K}^{0}{ }_{n, t}$ & 926 & 533 & $\mathrm{MPa} / \mathrm{mm}$ \\
\hline
\end{tabular}


It has to be mentioned that in addition and together with the bilinear model proposed by Alfano and Crisfield [21], the Puck criterion is used when modelling damage initiation [22]. This criterion is based on the material properties, stresses, and strains, and incorporates the limit values of the strains in the different modes. According to this criterion, damage initiation is related to a certain value of stiffness reduction. In this study, the Puck criterion was used for modelling the interface delamination for the four failure modes of damage initiation related to the fibers and the matrix. These four modes are Tensile Fiber Failure Mode, Compressive Fiber Failure Mode, Tensile Matrix Failure Mode, and Compressive Matrix Failure Mode.

The damage evolution law utilized in the numerical simulations is based on the instant stiffness reduction. The stiffness reduction is used to define how the composite interfaces are degraded because of the damage. Accordingly, this stiffness reduction can vary between 0 and 1 , where 0 indicates no reduction in the stiffness and 1 is associated with complete stiffness loss. In this study, we have assumed that there is an $80 \%$ reduction of stiffness reduction due to the delamination/damage for the four modes of damage.

\subsection{Model Verification}

To verify the results obtained using the finite element model and to validate the model, the finite element results are compared with the experimental results obtained in the paper of Saghafi et al. [17]. The numerical and the experimental results are presented in Table 2. The table represents the damaged area on the laminates with and without polycaprolactone nanofibers as a result of the impact with energies of $24 \mathrm{~J}$ and $36 \mathrm{~J}$. From the table, it can be seen that the numerical results show the same trend as the reported experimental results and the delaminated area decreases for the nano modified samples for both cases of impact. Furthermore, it should be noted that the experimentally measured damaged area is in very good agreement with the damaged area obtained in the numerical simulations, which comes to further validate the results of the numerical simulations.

Table 2. Area damaged $\left(\mathrm{mm}^{2}\right)$ in pristine and nano composite due to the 24 and $36 \mathrm{~J}$ energy impact.

\begin{tabular}{cccc}
\hline Energy & Sample & Experimental [17] & Numerical \\
\hline \multirow{2}{*}{ 24 J } & Pristine & $170 \mathrm{~mm}^{2}$ & $175 \mathrm{~mm}^{2}$ \\
& Nano & $125 \mathrm{~mm}^{2}$ & $126 \mathrm{~mm}^{2}$ \\
\hline \multirow{2}{*}{$36 \mathrm{~J}$} & Pristine & $260 \mathrm{~mm}^{2}$ & $275 \mathrm{~mm}^{2}$ \\
& Nano & $197 \mathrm{~mm}^{2}$ & $196 \mathrm{~mm}^{2}$ \\
\hline
\end{tabular}

The experimental results were conducted using a drop-weight impact machine as reported in [17]. For this purpose, the same composite specimens are impacted at 24 and $36 \mathrm{~J}$ using a drop-weight impact machine. The impactor consists of a steel spherical ball with a diameter and weight of $12.7 \mathrm{~mm}$ and $1.22 \mathrm{~kg}$, respectively. Each impact was repeated three times for configuration.

\section{Results and Discussion}

This section analyzes the effect of polycaprolactone nanofibers on the dynamic and the impact behavior of glass fiber composite laminates. The section is divided into three parts. The first and second parts are devoted to the effect of polycaprolactone nanofibers on the natural frequencies and the damping, respectively. The last part investigates the effect of polycaprolactone nanofibers on the impact damage resistance of glass fiber composite laminates.

\subsection{Effect of Polycaprolactone Nanofibers on the Natural Frequencies}

The effect of polycaprolactone nanofibers on the natural frequencies of the composite laminates is analyzed in this paragraph. For that purpose, the first five natural frequencies of the composites with and without polycaprolactone nanofibers are determined using the results from the vibration 
test explained in Section 3. Table 3 shows the natural frequencies for the pristine and nano modified composites and the variation of the natural frequencies in percentage due to the incorporation of polycaprolactone nanofibers.

Table 3. Effect of polycaprolactone nanofibers on the natural frequencies.

\begin{tabular}{cccc}
\hline Frequency $(\boldsymbol{f})$ & Pristine $\mathbf{( H z )}$ & Nano $(\mathbf{H z})$ & Variation $(\%)$ \\
\hline First & 484.5 & 461.5 & 4.7 \\
Second & 930.9 & 923.2 & 0.8 \\
Third & 1373.8 & 1369.8 & 0.3 \\
Fourth & 1857.5 & 1843.2 & 0.8 \\
Fifth & 2303.8 & 2278.0 & 1.2 \\
\hline
\end{tabular}

The results reveal that the natural frequencies of the composites with polycaprolactone nanofibers are smaller compared to the pristine specimens. However, these changes are rather small and the variation of the natural frequencies is not significant (lower than $5 \%$ ). In our view, the incorporation of nanofibers into the laminates induces little reduction in the composite stiffness, which slightly reduces the natural frequencies. In other words, the nanofibers create a matrix enrichment at the ply-to-ply interfaces, causing an increment of the matrix content, which reduces the composite stiffness and consequently the natural frequencies. These findings are in line with other results reported in the literature. For example, Ref. [23] reported that the natural frequencies of glass fiber composites showed minuscule changes (less than $4 \%$ ) due to the inclusion of nylon nanofibers. Similar results were found in $[24,25]$, which reported very small changes in the natural frequencies due to the inclusion of carbon nanofibers and nanotubes, respectively. In conclusion, it can be said that the changes of the natural frequencies depend on the properties of the nanofiber interleaved. For this particular case, the effect of the polycaprolactone nanofibers on the natural frequencies is miniscule and inconclusive as these variations are in the region of experimental and measurement error.

\subsection{Effect of Polycaprolactone Nanofibers on the Damping Ratio}

This paragraph analyses the effect of polycaprolactone nanofibers on the damping ratio of glass fiber composite laminates. The damping ratio for the laminates with and without nanofibers is calculated using the method described in Section 3. Table 4 illustrates the damping of the pristine and nano modified composites. Additionally, the table also includes the variation of damping ratio due to the reinforcement with nanofibers.

Table 4. Effect of polycaprolactone nanofibers on the damping ratio.

\begin{tabular}{lccc}
\hline & Pristine (Dimensionless) & Nano (Dimensionless) & Variation (\%) \\
\hline Damping & 0.01208 & 0.01277 & 5.7 \\
\hline
\end{tabular}

The results indicate that the damping of the nano modified composites is higher with respect to the damping of the pristine panels. It can be seen that the damping ratio increased by $5.7 \%$ due to the reinforcement with polycaprolactone nanofibers. This can be attributed to the fact that nanofibers are able to dissipate energy, giving the nano modified composite a higher damping ratio. Thus, the nanofibrous mats play the role of dampers. Our results are in good agreement with other results published previously. For example, the authors from [8] suggest that the damping of glass fiber composites increased by $36 \%$ due to the interleaving with nylon nanofibers. Other works, such as [26,27], found that the damping of composite laminates increased up to $28 \%$ and $108 \%$ because of the interleaving with jute nanofibers and carbon nanotubes respectively. As a conclusion, it can be said that the inclusion of polycaprolactone nanofibers in the composite interfaces increases the damping ratio because the nanofibers act as dampers. 
Therefore, composites interleaved with polycaprolactone nanofibers can be potentially used to reduce the amplitude of the vibrations in composite structures such as aircrafts, wind turbines, or bridges.

\subsection{Effect of Polycaprolactone Nanofibers on the Impact Damage Behaviour}

The aim of this section is to analyse the effect of polycaprolactone nanofibers on the impact damage resistance of glass fibre composites. For this study, the finite element model introduced in Section 4.1 is used to simulate the damage caused by impacts with energies of $24 \mathrm{~J}$ and $36 \mathrm{~J}$ in the pristine and nano modified composites.

The composite beams are subjected to impacts using energies of $24 \mathrm{~J}$ and $36 \mathrm{~J}$, as detailed in Figure 4 . The figure shows that the experimental and numerical force-displacement curves for the same energy impact are almost equal. Therefore, it can be concluded that the total impact energy used in the experiments and numerical simulations is the same. From the figure, the peak forces and displacements for the 24 and $36 \mathrm{~J}$ energy impacts can also be clearly observed. Therefore, according to our simulations, the peak force increases from 3795 to $4821 \mathrm{~N}$ when the energy of the impact varies between 24 and $36 \mathrm{~J}$. The mechanical impacts are located at the center of the specimen and each impact is applied at the same location for each test. The composite beams are fixed using clamp-clamp boundary conditions. Therefore, the composite specimens are clamped using fixed supports at both ends of the composite beams.

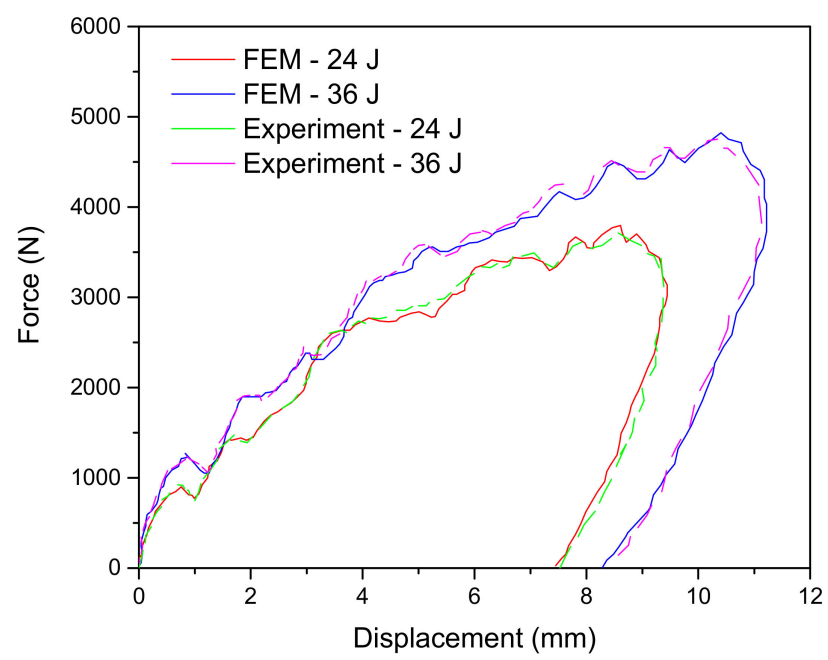

Figure 4. Comparison between the experimental and numerical force-displacement curves for the energy impacts at $24 \mathrm{~J}$ and $36 \mathrm{~J}$.

The results obtained using the finite element model simulations are illustrated in Figure 5. The legend scale on the left refers to the level of damage in the composite specimen, where the strong blue colour $(0 \%)$ represents the undamaged area of the composite and the red colour $(100 \%)$ represents the severely damaged area of the composite. The green colour in between (50\%) corresponds to damage states, which are in between the above two, the non-damaged and the severely damaged states, where the composite specimens are partially damaged. From the simulations, it can be clearly appreciated that nano composites are less damaged than the pristine panels for the two cases investigated (24 and $36 \mathrm{~J})$. Therefore, it can be concluded that according to the finite element modelling and experiments, the incorporation of polycaprolactone nanofibers reduces the delaminated area by about $27 \%$ for the two energy levels at 24 and $36 \mathrm{~J}$. This can be attributed to the good adhesion between polycaprolactone nanofibers and epoxy resin and the formation of heterogeneous separated phases on the composites interfaces, which increases the energy dissipation [28]. Additionally, the figure also shows that the most severe damage in the composite is located in the impacted zones (red area). 


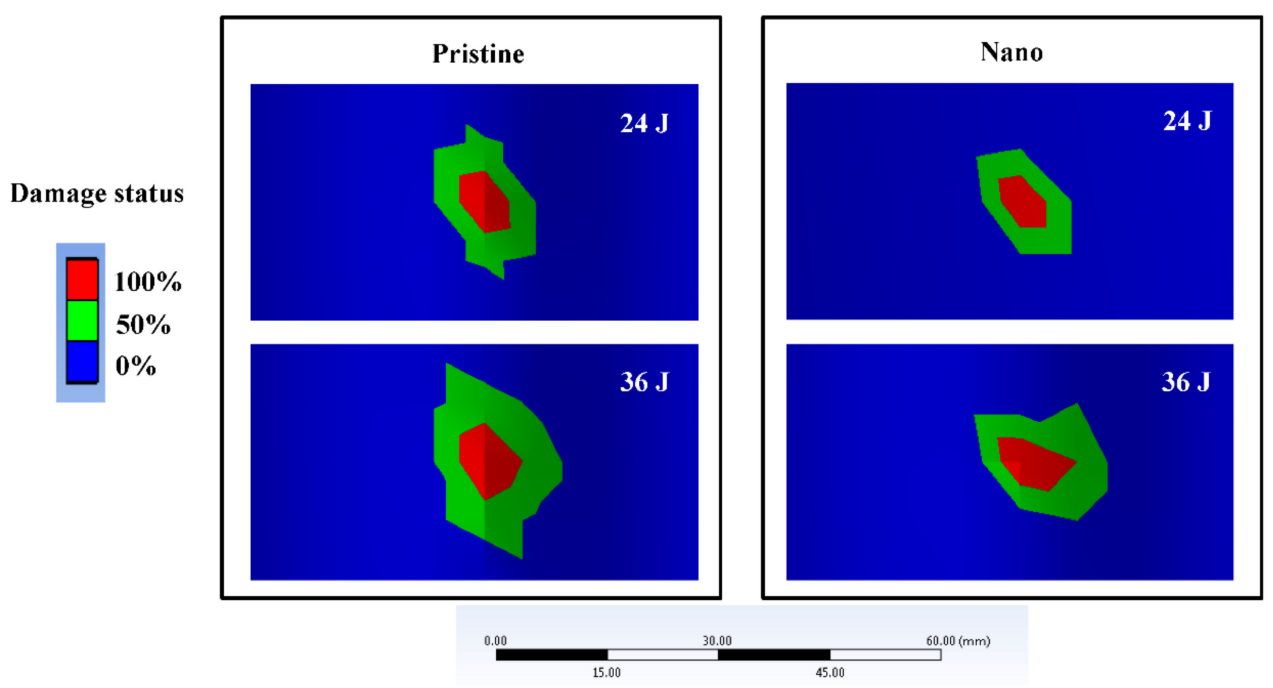

Figure 5. Area damaged after the energy impact at 24 and $36 \mathrm{~J}$ for the pristine and nano composites.

Experimental results show that the area damaged as a result of the $24 \mathrm{~J}$ impact is 170 and $125 \mathrm{~mm}^{2}$ for the pristine and nano composites, respectively [17], and our numerical simulations confirm that the damaged area decreased from 175 to $126 \mathrm{~mm}^{2}$ as a result of the incorporation of polycaprolactone nanofibers. The same trend is found for an impact with $36 \mathrm{~J}$ energy, where the area damaged in the composite laminates decreased by around $26 \%$ due to the reinforcement with polycaprolactone nanofibers. Therefore, the results obtained experimentally and numerically confirm that the composites reinforced with polycaprolactone nanofibers are less susceptible to impact damage than pristine panels. Similar results have been reported previously in other works. For example, Ref. [29] reported that the addition of nylon nanofibers to the interfaces of carbon fiber epoxy composites significantly increased the threshold impact force (the force to cause initiation of impact damage) up to $60 \%$. Additionally, this study shows that the impact damage area decreases considerably due to the interleaving with nylon nanofibers. Other works, such as [30], indicated that the incorporation of a mixture of polycaprolactone and nylon nanofibers into the composite ply interfaces could decrease the impact damage area by up to $59.3 \%$ in glass fiber epoxy composites. Others authors, such as [31,32], suggest that the interleaving with other electrospun nanofibers such as polyvinylidene fluoride and polyacrylonitrile is not a good choice for toughening epoxy and improving the impact damage resistance of glass fiber/epoxy laminates. In conclusion, it can be said that the interleaving with polycaprolactone nanofibers decreases the impact damage area in glass fiber epoxy composites by more than $20 \%$. This discovery is of the utmost importance for structures made of composite materials (e.g., aircrafts or wind turbines), where the impacts caused by bird strikers or hailstorms are a main concern.

\section{Conclusions}

This research investigates some important applied properties of polycaprolactone modified glass fiber epoxy composites. It deals with their dynamic properties and their impact resistance. The performed experimental investigations suggest that the incorporation of polycaprolactone nanofibers into composite interfaces increases the damping ratio and does not affect to the natural frequencies. This is important from the view point of using such materials as part of any structural elements that experience vibration. The interleaving with polycaprolactone nanofibers is potentially capable of reducing the amplitude of such vibration.

The impact resistance of materials is very important in a number of industries, including aircraft design and production. The numerical investigation offered in this research shows that the incorporation of polycaprolactone nanofibers can improve the impact resistance of glass fiber epoxy layered composites. Thus, polycaprolactone nanofibers can be used to develop composite materials 
with improved impact resistance which can be a used for an important number of applications, including aircrafts and wind turbines.

This work presents solid progress toward the practical applications of composites reinforced with polycaprolactone nanofibers as per example the control of vibrations and prevention of damage from delamination.

Author Contributions: C.G. designed, wrote, and revised the paper. I.T. supervised the research and revised the paper and A.Z. provided the composite specimens.

Funding: This research received no external funding.

Acknowledgments: The authors wish to specially thank the University of Bologna for their technical assistance and valuable support in terms of materials and equipment.

Conflicts of Interest: The authors declare no conflict of interest.

\section{Appendix A}

Table A1. Material Constants used to simulate the layers of unidirectional glass fiber epoxy composite supplied by ANSYS Workbench Engineering Data.

\begin{tabular}{cc}
\hline Constant & Value \\
\hline Young's Modulus X direction & $45 \mathrm{GPa}$ \\
Young's Modulus Y direction & $10 \mathrm{GPa}$ \\
Young's Modulus Z direction & $10 \mathrm{GPa}$ \\
Poisson's Ratio XY & 0.3 \\
Poisson's Ratio YZ & 0.4 \\
Poisson's Ratio XZ & 0.3 \\
Shear Modulus XY & $5 \mathrm{GPa}$ \\
Shear Modulus YZ & $3.8 \mathrm{GPa}$ \\
Shear Modulus XZ & $5 \mathrm{GPa}$ \\
\hline
\end{tabular}

\section{Appendix B}

Since the maximum traction $\left(T_{\max }\right)$, displacement at debonding $\left(\delta_{\mathrm{c}}\right)$, and ratio of $\delta^{*}$ and $\delta_{\mathrm{c}}(\alpha)$ cannot be determined by experimental tests, these values are determined through a comparison of the experimental results with the numerical simulations of the same tests, allowing for an estimation of the unknown material properties for the cohesive zone model. By definition, the area under the triangle (see Figure 3) corresponds to the critical interlaminar fracture energy for the glass fiber composites. Therefore, the numerical critical fracture energy for the pristine and nano composites is $675 \mathrm{~J} / \mathrm{m}^{2}$ and $490 \mathrm{~J} / \mathrm{m}^{2}$, respectively. These results are in the range of other composite laminates with similar characteristics.

\section{References}

1. Daelemans, L.; Vander, H.S.; Baere, I.; Rahier, H.; Paepegem, W.; Clerk, K. Damage resistant composites using electrospun nanofibers: A multiscale analysis of the toughening mechanisms. ACS Appl. Mater. Interfaces 2016, 8, 11806-11818. [CrossRef] [PubMed]

2. Shinde, D.K.; Kelkar, A.D. Effect of TEOS electrospun nanofiber modified resin on interlaminar shear strength of glass fibre/epoxy composite. Int. J. Mater. Metall. Eng. 2014, 8, 54-59.

3. Xiao, L.; Xu, L.; Yang, Y.; Zhang, S.; Huang, Y.; Bielawsky, C.W.; Geng, J. Core-shell structured polyamide 66 nanofibers with enhanced flame retardancy. ACS Omega 2017, 2, 2665-2671. [CrossRef]

4. Palazzetti, R.; Zucchelli, A. Electrospun nanofibers as reinforcement for composite laminates materialsA review. Compos. Struct. 2017, 182, 711-727. [CrossRef]

5. Jiang, S.; Chen, Y.; Duan, G.; Mei, C.; Greiner, A.; Agarwal, S. Electrospun nanofiber reinforced composites: A review. Polym. Chem. 2018, 9, 2685-2720. [CrossRef] 
6. Garcia, D.; Palazzetti, R.; Trendafilova, I.; Fiorini, C.; Zucchelli, A. Vibration based delamination diagnosis and modelling for composite laminate plates. Compos. Struct. 2015, 130, 155-162. [CrossRef]

7. Garcia, D.; Tcherniak, D.; Trendafilova, I. Damage Assessment for wind turbine blades based on a multivariate statistical approach. J. Phys. Conf. Ser. 2015, 1, 628. [CrossRef]

8. Garcia, C.; Wilson, J.; Trendafilova, I.; Yang, L. Vibratory behaviour of glass fibre reinforced polymer (GFRP) interleaved with nylon nanofibers. Compos. Struct. 2017, 176, 923-932. [CrossRef]

9. Palazzetti, R.; Zucchelli, A.; Trendafilova, I. The self-reinforcing effect of nylon 6,6 nano-fibres on CFRP laminates subjected to low-velocity impact. Compos. Struct. 2013, 106, 661-671. [CrossRef]

10. Saghafi, H.; Palazzetti, R.; Zucchelli, A.; Minak, G. Influence of electrospun nanofibers on the interlaminar properties of unidirectional epoxy resin/glass fiber composite laminates. J. Reinf. Plast. Compos. 2015, 34, 907-914. [CrossRef]

11. Palazzetti, R. Flexural behavior of carbon and glass fiber composite laminates reinforced with nylon 6,6 electrospun nanofibers. J. Compos. Mater. 2015, 49, 3407-3413. [CrossRef]

12. Beylergil, B.; Tanoglu, M.; Aktaş, E. Enhancement of interlaminar fracture toughness of carbon fiber-epoxy composites using polyamide-6,6 electrospun nanofibers. J. Appl. Polym. Sci. 2017, 10, 45244. [CrossRef]

13. Beckermann, G.W.; Pickering, K.L. Mode I and mode II interlaminar fracture toughness of composite laminates interleaved with electrospun nanofiber veils. Compos. Part A 2015, 72, 11-21. [CrossRef]

14. Molnar, K.; Kostakova, E.; Meszaros, L. The effect of needleless electrospun nanofibrous interleaves on mechanical properties of carbon fabrics/epoxy laminates. Express Polym. Lett. 2014, 8, 62-72. [CrossRef]

15. Manh, C.V.; Choi, H.J. Enhancement of interlaminar fracture toughness of carbon fiber/epoxy composites using silk fibroin electrospun nanofibers. Polym. Plast. Technol. Eng. 2016, 55, 1048-1056. [CrossRef]

16. Akangah, P.; Shivakumar, K. Impact damage resistance and tolerance of polymer nanofiber interleaved composite laminates. In Proceedings of the 53rd AIAA/ASME/ASCE/AHS/ASC Structures, Structural Dynamics and Materials Conference, Honolulu, HI, USA, 23-26 April 2012.

17. Saghafi, H.; Brugo, T.; Minak, G.; Zucchelli, A. Improvement the impact damage resistance of composite materials by interleaving polycaprolactone nanofibers. Eng. Solid Mech. 2015, 3, 21-26. [CrossRef]

18. Schueren, L.V.; Schoenmaker, B.; Kalaoglu, O.I.; Clerk, K. An alternative solvent system for the steady state electrospinning of polycaprolactone. Eur. Polym. J. 2011, 47, 1256-1263. [CrossRef]

19. Rahman, N. An efficient method for frequency calculation of an audio signal. Presidency 2013, 2, 41-45.

20. Casiano, M.J. Extracting Damping Ratio from Dynamic Data and Numerical Solutions; Marshal Space Flight Center: Huntsville, AL, USA, 2016; p. 2.

21. Alfano, G.; Crisfield, M.A. Finite element interface models for the delamination analysis of laminated composites: Mechanical and computational issues. Int. J. Numer. Methods Eng. 2001, 50, 1701-1736. [CrossRef]

22. Deuschle, H.M.; Puck, A. Application of the Puck failure theory for fibre-reinforced composites under three-dimensional stress: Comparison with experimental results. J. Compos. Mater. 2012, 47, 827-846. [CrossRef]

23. Garcia, C.; Trendafilova, I.; Zucchelli, A.; Contreras, J. The effect of nylon nanofibers on the dynamic behaviour and the delamination resistance of GFRP composites. In Proceedings of the International Conference on Engineering Vibration ICoEV, MATEC Web Conference, Sofia, Bulgaria, 4-7 September 2017; Volume 148, p. 14001.

24. Gou, J.; O'Braint, S.; Gu, H.; Song, G. Damping augmentation of nanocomposites using carbon nanofiber paper. J. Nanomater. 2006, 2006, 32803. [CrossRef]

25. Her, S.H.; Lai, C.Y. Dynamic behaviour of nanocomposites reinforced with multi-walled carbon nanotubes (MWCNTs). Materials 2013, 6, 2274-2284. [CrossRef] [PubMed]

26. Padal, K.T.B.; Ramji, K.; Prasad, V.V.S. Damping behaviour of jute nano fibre reinforced composites. Int. J. Emerg. Technol. Adv. Eng. 2014, 4, 753-759.

27. Kordani, N.; Fereidoon, A.; Ashoori, M. Damping augmentation of nanocomposites using carbon nanotube/epoxy. J. Struct. Dyn. 2011, 3, 1605-1615.

28. Zhang, J.; Yang, T.; Lin, T.; Wang, C.H. Phase morphology of nanofiber interlayers: Critical factor for toughening carbon/epoxy composites. Compos. Sci. Technol. 2012, 72, 256-262. [CrossRef]

29. Akangah, P.; Lingaiah, S.; Shivakumar, K. Effect of nylon-66 nano-fiber interleaving on impact damage resistance of epoxy/carbon fiber composite laminates. Compos. Struct. 2010, 92, 1432-1439. [CrossRef] 
30. Saghafi, H. Mechanical Behaviour of Flat and Curved Laminates Interleaved by Electrospun Nanofibers. Ph.D. Thesis, University of Bologne, Bologne, Italy, 2013.

31. Saghafi, H.; Palazzetti, R.; Zucchelli, A.; Minak, G. Impact response of glass/epoxy laminate interleaved with nanofibrous mats. Eng. Solid Mech. 2013, 1, 85-90. [CrossRef]

32. Saghafi, H.; Palazzetti, R.; Minak, G.; Zucchelli, A. Effect of PAN nanofiber interleaving on impact damage resistance of GFRP laminates. In Proceedings of the 6th International Conference on NanomaterialsResearch and Application, Brno, Czech Republic, 5-7 November 2014.

(C) 2018 by the authors. Licensee MDPI, Basel, Switzerland. This article is an open access article distributed under the terms and conditions of the Creative Commons Attribution (CC BY) license (http://creativecommons.org/licenses/by/4.0/). 